\title{
Com a ciclosporina na mira
}

\section{Target on cyclosporine}

Mulher de 38 anos, que recorre à consulta por úlceras orais e genitais com episódio de uveíte anterior aguda bilateral não granulomatosa com oclusão do vaso da retina nasal inferior, adenopatias axilares e HLA B7 e B51 positivos, medicada com prednisolona e inibidor da calcineurina. Quatro dias antes do internamento e cerca de um ano após o diagnóstico de doença de Behçet (DB) emerge quadro de vertigens, náuseas e vómitos acompanhado de cefaleia holocraniana. À observação, diplopia intermitente na levoversão do olhar com desaparecimento da imagem sombra à esquerda na oclusão do olho esquerdo, nistagmo horizontal na dextroversão, Weber lateralizado à esquerda, parésia do VI par esquerdo, marcha com base alargada com ligeiro desvio direito. Tomografia computorizada crânio-encefálica (TC-CE) sem alterações. Ressonância magnética crânio-encefálica (RM-CE) em que se verificou lesão hipointensa em T1 e hiperintensa nas sequências de TR longo (imagens 1 e 5), interessando 0 bulbo e com ligeira extensão à porção posterior da ponte, sem restrição à difusão das moléculas de água ou realce após a administração de gadolínio (imagem 5), condicionando ligeira expansão da medula oblonga e discreta atenuação dos espaços de circulação envolventes. Não se observa blooming de sinal na sequência $2^{*}$ traduzindo depósito de hemosiderina - hemorragia não recente (imagem 4), aspectos que se coadunam com a hipótese clínica de Neuro-Behçet.

Realizada terapêutica com pulso de metilprednisolona e ciclofosfamida com reversão das alterações objetivadas. Realizada RM-CE de controlo aos 3 meses com franca melhoria. Atualmente assintomática, sob terapêutica com azatioprina, colquicina e prednisolona $5 \mathrm{mg}$.

0 neuro-Behçet é uma complicação rara (11-20\% em doentes com diagnóstico estabelecido de DB), sendo o diagnóstico de uma importância fulcral pela morbi-mortalidade associada. A utilização de corticoterapia está preconizada na doença moderada a severa e deve ser considerada a utilização de altas doses em quadros agudos e graves com risco de vida ou de lesão de órgão. Manteve-se ainda a terapêutica com colchicina, já que é eficaz na apresentação muco-cutânea da doença. A utilização da ciclosporina quando a doença tem envolvimento exclusivamente ocular parece ser vantajosa face à ciclofosfamida $^{1,2}$. No entanto, considerando a frequência da neuro-toxicidade associada ao fármaco, o uso do mesmo pode dificultar a diferenciação clínica entre os efeitos adversos do fármaco e envolvimento neurológico associado à $\mathrm{DB}^{3}$. Quando há documentação de lesão do SNC, o uso de ciclosporina é desaconselhado 4 .

\section{Bibliografía}

1. Ozyazgan Y, Yurdakul S, Yazici H, Tüzün B, I çimen A, Tüzün Y, et al. Low dose cyclosporin A versus pulsed cyclophosphamide in Behçet's syndrome: a single masked trial. Br J Ophthalmol. Abril de 1992;76(4):241-3.

2. BenEzra D, Cohen E, Chajek T, Friedman G, Pizanti S, de Courten C, et al. Evaluation of conventional therapy versus cyclosporine A in Behçet's syndrome. Transplant Proc. Junho de 1988;20(3 Suppl 4):136-43.

3. Kötter I, Günaydin I, Batra M, Vonthein R, Stübiger N, Fierlbeck G, et al. CNS involvement occurs more frequently in patients with Behçet's disease under cyclosporin $\mathrm{A}$ (CSA) than under other medications--results of a retrospective analysis of 117 cases. Clin Rheumatol. Julho de 2006;25(4):482-6.

4. Hatemi G, Silman A, Bang D, Bodaghi B, Chamberlain AM, Gul A, et al. EULAR recommendations for the management of Behçet disease. Ann Rheum Dis. Dezembro de 2008;67(12):1656-62.

\section{Diagnóstico: NeuroBehçet}

Ana Pinheiro Sá, Milton Camacho

Serviço de Medicina 1B - Hospital Santa Maria - Centro Hospitalar Lisboa Norte
Imagem 1. T1 sagital da linha média. Lesão hipointensa interessando o bulbo e com ligeira extensão à porção posterior e inferior da ponte, condicionando ligeira expansão bulbar e discreta atenuação dos espaços de circulação de liquor envolventes

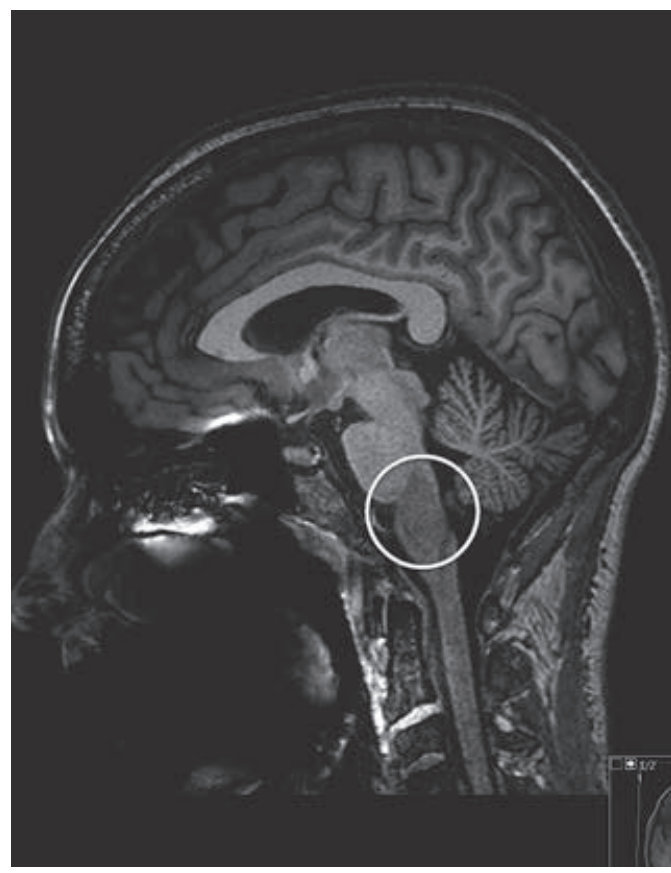

Imagem 2. T1 coronal. Lesão hipointensa interessando o bulbo

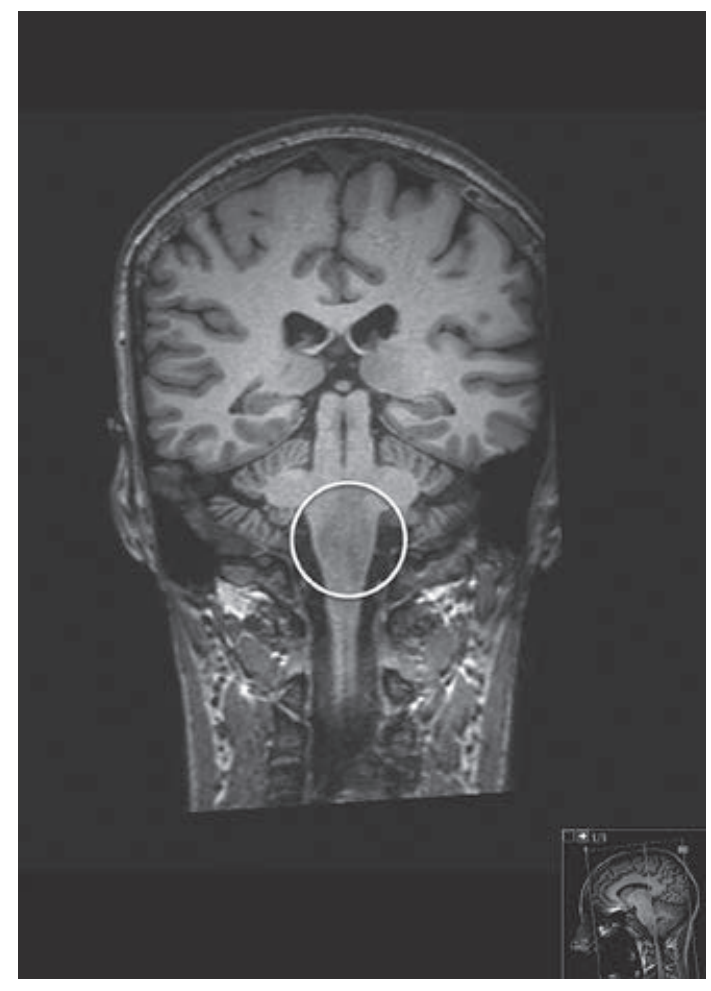

